\title{
Perceptions toward Artificial Intelligence among Academic Library Employees and Alignment with the Diffusion of Innovations' Adopter Categories
}

\section{Brady D. Lund, Isaiah Omame, Solomon Tijani, and Daniel Agbaji}

\begin{abstract}
Artificial intelligence (Al) has emerged as a topic of interest among information technology innovators. As Al is refined, practical uses of the technology to improve the transfer of information are increasingly investigated, developed, and adopted in a variety of public environments, including in libraries. Given the relatively recent emergence of $\mathrm{Al}$ in this respect, it presents an opportunity to investigate the emergence of public perceptions toward the innovation and the relationship this holds with the adoption of emerging technologies, as envisioned in Roger's Diffusion of Innovations model. This study describes the results of a survey of practicing librarians regarding the adopter category (innovator, early adopter, early majority, late majority, laggard) with which they identify and the relationship of this identification with perceived knowledge and perceptions of Al technology within and outside the library environment. The findings of this survey have both theoretical implications for the Diffusion model within the library technology context as well as practical implications for supporting the process of diffusion of emerging technologies among academic library employees.
\end{abstract}

Artificial intelligence (AI) is a technological innovation of increasing interest to the general public as well as within the academic library environment. ${ }^{1}$ Given the early stage in the development of this technology and its adoption for public use, there is a unique opportunity to examine a cross-section of librarians regarding the Diffusion of Innovations model and perceptions of AI. No study of this extent has yet been published in the scholarly literature in library and information science (LIS). Such an examination may prove beneficial both to the understanding of diffusion of innovations theory as well as perceptions of academic library employees toward AI in general. The findings may assist academic library administrators and tech-inclined employees as they aim to garner greater receptiveness among colleagues toward adopting AI technology in their libraries.

Artificial intelligence (AI) can be defined in many ways, as noted throughout scholarly and general literature, including a recent article published in Forbes. ${ }^{2}$ Russell and Norvig, in

Brady D. Lund is a doctoral student in the School of Library and Information Management at Emporia State University; email: blund2@g.emporia.edu. Isaiah Omame is assistant librarian at Federal University of Lafia; email: omameazy@gmail.com Solomon Tijani is assistant researcher at the Nigeria Institute of Social and Economic Research; email: tijanisolomon@gmail.com. Daniel Agbaji is a software developer associate at Flint Hills Resources; email:dagbaji1@gmail.com. @2020 Brady D. Lund, Isaiah Omame, Solomon Tijani, and Daniel Agbaji, Attribution-NonCommercial (https://creativecommons.org/licenses/by-nc/4.0/) CC BY-NC. 
their seminal textbook on AI, provide eight unique definitions that give different perspectives toward the art and science of creating a system that can make intelligent decisions. ${ }^{3} \mathrm{Cox}$, Pinfield, and Rutter ${ }^{4}$ use a definition from Tredinnick: (AI is) "a cluster of technologies and approaches to computing focused on the ability of computers to make flexible rational decisions in response to unpredictable environmental conditions. ${ }^{5} \mathrm{~A}$ functional definition for this study is gleaned from the work of AI researchers Keith Frankish and William Ramsey in the Cambridge Handbook of Artificial Intelligence: "Artificial intelligence is a cross-disciplinary approach to understanding, modeling, and replicating intelligence and cognitive processes by invoking various computational, mathematical, logical, mechanical, and even biological principles and devices," often from a pragmatic (smart systems design) perspective. ${ }^{6}$ In a library and information organization, a use of AI might include creating a program that offers automated reference services or scans the text of books to identify appropriate subject categories. ${ }^{7}$ On the design side, artificial intelligence requires highly complex programming logic and understanding of statistical and computing principles; however, on the practical side (as would be used by libraries), what is most needed is simply a change in thought about what library technology is and can become. ${ }^{8}$

Artificial intelligence is arguably the next frontier in an evolution of computing technology that has seen the development of mobile computing and ultra-fast processors. The multitude of possible uses for AI (affecting virtually all aspects of our lives, just as with the innovations of the internet, personal computers, and mobile phones) has led to the creation of a multibillion dollar industry, which could easily become a multitrillion dollar industry before all is said and done. ${ }^{9}$ It is important for libraries to investigate AI technologies as they develop and integrate them as appropriate.

\section{Research Questions}

The following research questions were developed to address topics of AI use in libraries and the theoretical framework used for the study:

1. What are the perceptions of academic librarians worldwide toward the prospect of artificial intelligence in everyday life and within the library environment?

2. Do perceptions of academic librarians toward AI vary in accordance with their adopter category, as described in Roger's model of Diffusion of Innovations?

\section{Literature Review}

Discussion of artificial intelligence in library and information science literature has existed for nearly a half-century. Library technology pioneer F.W. Lancaster took interest in the topic in the mid-1970s and continued to investigate use of AI in libraries systems for several decades..$^{10}$ Tom Suprenant, in 1983, described artificial intelligence as a technology with the potential to "eventually handle the work of an entire (library) department." ${ }^{11}$ In 1987, Linda Smith reviewed the literature within artificial intelligence to identify potential applications in libraries. ${ }^{12}$ Most of these works, however, were largely theoretical rather than examining practical applications.

From a practical standpoint, the use of artificial intelligence in libraries is new and not understood well. Some of the efforts to integrate AI started from the earlier ideas of the late 1980s/1990s, but are just now on the verge of becoming a reality. ${ }^{13}$ Several libraries have recently found compelling uses of $\mathrm{AI}$, such as to support library systems for the benefit of 
library patrons and employees in Iran, ${ }^{14}$ as well as the use of AI in assisted information literacy instruction. ${ }^{15}$ In 2019, Finley described how a library has prepared patrons for a shift to a greater role for AI in everyday life as well as in libraries, using a diversity of programming and maker kits that incorporate AI activities. ${ }^{16}$

Wood and Evans investigated librarians' perceptions toward artificial intelligence in $2018 .{ }^{17}$ There are several avenues for future investigation, based on their work. Their study focused heavily on the use of Supercomputers (like IBM's Watson) in libraries, asking respondents to identify what areas of the library this technology might be implemented and how soon they would expect that implementation. The results are compelling (most respondents believe AI will play a major role in libraries within the next three decades, resource discovery and reference being the most likely areas), ${ }^{18}$ but the questions are somewhat limited by defining $\mathrm{AI}$ as the researchers did. Furthermore, the study did not provide a strong grounding in the literature or theory of LIS and other fields, with only three references to other resources. This present study offers a more comprehensive look at librarian perspectives toward VR.

A recent study by Andrew Cox, Stephen Pinfield, and Sophie Rutter investigated "thought leader" views toward AI and libraries. ${ }^{19}$ In the study, the researchers interviewed "33 library directors, library commenters and experts and publishing." 20 The interviewees, in general, expressed optimism about the future of artificial intelligence in libraries in such roles as support within information discovery tools and machine-readable collections, assistance in research production and scholarly communication, and support for teaching and learning. However, the interviewees also expressed some concerns about AI, such as fear of job reduction in libraries, lack of relevant developments within AI for libraries, and privacy and security of data.

In March 2019, American Library Association president Loida Garcia-Febo wrote about the emergence of artificial intelligence and budding ways in which it has been used in libraries and related concerns, also noting that "it's clear that while AI can be useful, it also raises familiar concerns about privacy, intellectual freedom, authority, and access." 21 From articles like Garcia-Febo's, it is clear that AI has become a topic of interest, confusion, and possibly concern among many in the field of library and information science. A more detailed understanding about library professionals' feelings about AI, such as that which this study aims to provide, may be useful for education, outreach, and implementation efforts.

\section{Theoretical Framework}

Diffusion of Innovations (DOI) is one of the most (arguably the most, based on citations to DOI works) influential social theories of the 20th and 21st centuries. Though first proposed over a half-century ago, the DOI is considered a chronology- and discipline-transcendent theory that continues to be used with great regularity even in the present day. ${ }^{22}$ Diffusion refers to the adoption of individuals and groups of an innovation (some new technology, idea, or another innovation). The process of diffusion of innovations is described by Rogers as "An information-seeking and information-processing activity," where individuals use information about an innovation to determine whether or not they will adopt (use) this innovation. ${ }^{23}$

There are two major elements from Roger's Diffusion theory, in particular, that are studied and applied liberally across social science. The first is related to the study of rate and extent of diffusion. This element is found in the work of White ${ }^{24}$ and Minishi-Majanja and Kiplang'at. ${ }^{25}$ These authors studied how different rates of diffusion occurred among libraries in regard to specific information and communications technologies. A study of this type for artificial 
intelligence and libraries could be compelling; however, this technology is so new that adoption is likely to be very limited. In a 2017 paper published in the Journal for the Association for Information Science and Technology, Zhai, Ding, and Wang studied the rate/stages of diffusion through a citation analysis of scholarly research. ${ }^{26}$

The second element is related to Rogers' conception of adopter categories. Rogers identified five categories of adopters: innovators, the very first people to adopt an innovation; early adopters, the trendsetter of sorts, who does not hurry to adopt an innovation but evaluates and adopts the innovation only after determining its value; early majority, those who follow the leadership of the early adopters once value of the innovation has been established; late majority, those who are naturally skeptical toward an innovation and adopt the innovation later than average; and laggards, who are traditionalists that actively resist the innovation. ${ }^{27} \mathrm{By}$ using these adopter categories as a demographic variable for a population, it may be possible to examine how different categories of adopters view emerging topics differently. Iftakhar's "Google Classroom: What Works and How?" is an example of a study that uses this element of diffusion theory. ${ }^{28}$ This is the element with which the present study concerns itself. There has been little investigation of how adopter categories affect perceptions toward innovations in library and information organizations, and none pertaining to artificial intelligence technology.

Studies evaluating diffusion of innovations of information and communications technology have existed since the emergence of the theory, but they grew rapidly from the 1980s through the start of the new millennium..$^{29}$ Diffusion of information and communications technologies has been found, among general populations, to relate strongly to prior knowledge and experience with these types of technologies. ${ }^{30}$ While rate of diffusion has been found to vary from country to country, based on factors like information access and social practices and beliefs, adopter categories for general innovation adoption tend to be standard across geographical backgrounds. ${ }^{31}$

Diffusion of Innovations has been used as the theoretical framework of many recent impactful studies, both in scholarly articles and doctoral dissertations, in the discipline of LIS. For instance, Valenti studied how diffusion concepts influenced the adoption of innovation in higher education courses..$^{32}$ Neo and Calvert used a similar framework to study diffusion of social media innovations in New Zealand public libraries. ${ }^{33}$ Even more recently, in 2018 Liu and Hsu used the DOI lens to study the integration of technology into library information services, ${ }^{34}$ and Qazi, Raza, and Shah used the lens to study acceptance of e-books among university students in developing countries. ${ }^{35}$

Agarwal, Ahuja, Carter, and Gans examined the personality and beliefs of individuals belonging to different adopter categories, in the context of information technology adoption behavior. ${ }^{36}$ Zayim, Yildirim, and Saka examined differences in beliefs and practices among adopter categories in adopting educational technologies in the university classroom. ${ }^{37}$ Raynard analyzed how adopter categories describe the adoption behaviors of students and faculty in regard to academic e-books and academic library electronic resources. ${ }^{38}$ The present study aims to build on these previous studies by examining alignment between adopter categories among librarians and perspectives toward artificial intelligence technology.

Librarians are potentially powerful advocates for the adoption of new technological innovations like AI, as key players in the diffusion of information to others. ${ }^{39}$ They are often leaders in the adoption of technologies, insofar as the technologies are useful for library services. However, as indicated with the diffusion of innovations theory and supported in many 
subsequent studies, individuals will only support the diffusion of innovations that they find valuable and nonthreatening. ${ }^{40}$

\section{Methods}

An electronic survey was created using Qualtrics and distributed via the International Federation of Library Associations' Information Technology and Academic and Research Libraries listservs. The population for the survey was academic librarians in public service roles. A copy of this survey is included as an appendix to this study.

Questions on the survey fall into one of three blocks: demographics, perspectives on AI, and outlook/optimism toward computer/internet technologies and the monopolies and conglomerates that produce these technologies. The purpose of asking this variety of questions is to cover the breadth of the two research questions for this study. The researchers sought to identify whether any significant difference exists in the perspectives of AI based on demographics (particularly, DOI adopter category), as well as whether perspectives toward emerging technologies in general and the companies that produce them may affect the outlook toward AI.

Distinct methods were used for analysis of the survey findings for each research question. For research question 1, descriptive statistics (mean/frequencies) are provided for each question. For research question 2, a pair of linear regressions are performed using the dependent variable of adopter category ("innovator/early adopter" vs "other" as dummy variables), and responses to other questions within the survey as explanatory variables. These regressions examine whether the responses to questions pertaining to knowledge, interest, and outlook toward artificial intelligence have a significant relationship with the category of adopter. Such an analysis has theoretical value as well as practical value (identification of variables that may assist in speeding up the diffusion process).

\section{Results}

The total number of respondents to the survey is 236 . While it is not easy to calculate the total number of academic librarians worldwide, this sample size is likely representative of a margin of error of about 5 percent. ${ }^{41}$ The age composition of survey respondents is 22 percent ages 29 and younger, 32 percent ages 30-39, 38 percent ages $40-49$, and 8 percent ages $50-59$. Two percent of respondents have less than a four-year degree, 16 percent have a four-year degree, 74 percent have a master's degree in library and information science (LIS), 2 percent have a master's degree in a non-LIS discipline; and 6 percent have a PhD. North America (41\%) and Africa (42\%) are disproportionally represented in the results, while South America, Europe, Asia, and Australia all represent between 2 and 8 percent of the survey respondents. With respect to the international distribution of the survey, no significant difference was found among respondents from any one continent and the others in responses to the questions.

In Roger's model of diffusion, adopters of a technology (innovation) are conceived as falling along a normal distribution, with innovators representing 2.5 percent of the population, early adopters representing 13.5 percent, early majority and late majority each representing 34 percent, and laggards representing 16 percent. Table 1 below displays those percentages (culminating in 100 percent of the total population) compared to responses of the sample population of this study regarding their adoption pattern related to library technology. In this study, innovators represent a whopping 13 percent, early adopters represent 38 percent, 
early majority 48 percent, late majority 9 percent, and laggards only 2 percent. This reflects a right skew in the distribution. The skew was not unanticipated, as the topic of this study is more likely to appeal to earlier adopters, as well as the fact that librarians, in general, tend to be more receptive than the general population toward new ideas and technologies.

\begin{tabular}{|c|c|c|}
\hline \multirow{3}{*}{ TABLE 1 } \\
Roger's Diffusion of Innovations Model and Composition of Survey Respondents \\
\hline $\begin{array}{c}\text { Categories of Innovators in } \\
\text { Roger's Model }\end{array}$ & \multicolumn{2}{|c|}{ Cumulative Percentage of Individuals } \\
\cline { 2 - 3 } & Standard Diffusion Model & Respondents of This Study \\
\hline Innovators & $2.5 \%$ & $13 \%$ \\
\hline Early Adopters & $16 \%$ & $40.7 \%$ \\
\hline Early Majority & $50 \%$ & $88.9 \%$ \\
\hline Late Majority & $84 \%$ & $98.1 \%$ \\
\hline Laggards & $100 \%$ & $100 \%$ \\
\hline
\end{tabular}

As shown in table 2, on a 7-point Likert scale (values 0-6), respondents indicate a knowledge of and optimism toward AI of about 5, which suggests moderately high levels for both. Most of the respondents to this survey are likely to be tech-inclined, based on the listservs in which the survey was distributed, but these high reported levels are still somewhat unexpected, given the still relatively nascent state of AI and AI research.

\begin{tabular}{|l|c|c|}
\hline \multicolumn{3}{|c|}{ TABLE 2} \\
Respondents' Knowledge and Optimism about Al \\
\hline Topic & Mean & Std. Dev. \\
\hline Rate your knowledge of artificial intelligence as a concept & 5 & 1.08 \\
\hline Rate your knowledge of trends in artificial intelligence & 4.64 & 1.21 \\
\hline $\begin{array}{l}\text { Rate your level of optimism about the future of artificial intelligence for } \\
\text { improving library service }\end{array}$ & 5.2 & 1.36 \\
\hline
\end{tabular}

Figure 1 displays responses to the dichotomous (yes/no) questions on the survey. Most respondents have no concern that AI would jeopardize their employment status. Respondents were also one-sided in their belief that AI would improve the lives of people. Responses are slightly more mixed as to whether privacy is of concern with AI. Among adopter categories, the innovators and early adopters are the two groups that had the largest margin of individuals concerned with privacy, while the early majority has the smallest percentage of respondents with concern. Forty percent of respondents read scholarly literature more than three hours per week. The innovator category has the largest proportion of respondents who read scholarly literature for three or more hours per week. The late majority has the smallest proportion of the respondents who read scholarly literature more than three hours per week, though the laggards group has the largest proportion that read no scholarly literature at all (in other words, a large proportion of late adopters read scholarly literature between one and three hours per week, while many laggards read no scholarly literature at all).

Regarding the perception of computer/Internet companies (those paving the way for AI), the majority of respondents believes these entities contribute to the good of society. There is a 


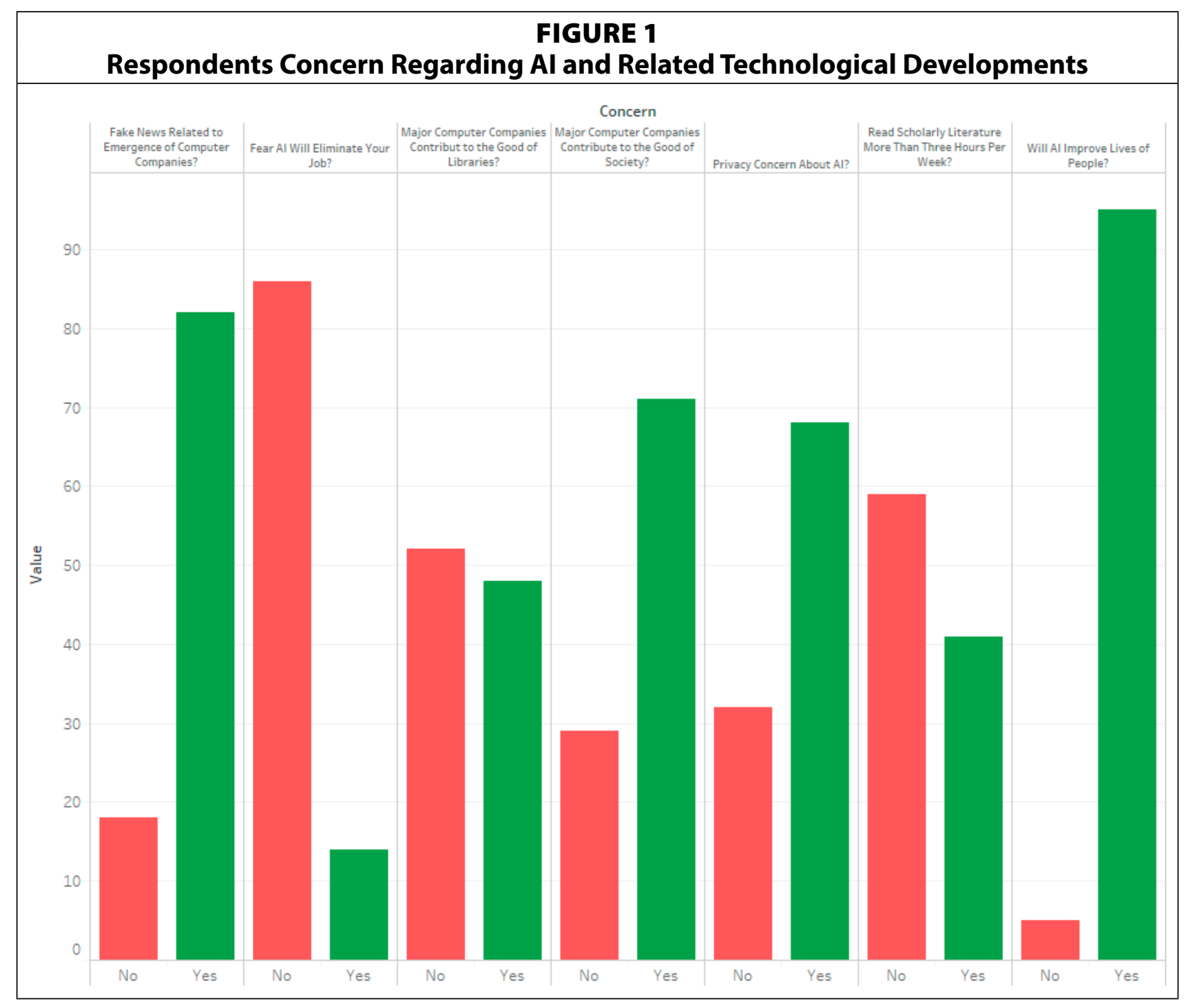

near 50/50 split in perception as to whether these companies contribute to the good of academic libraries. Innovators and early adopters are more likely to indicate both that computer/internet companies contribute to the good of society and the good of libraries. Those in the laggards category are more likely to indicate that computer/internet companies do not contribute to the good of libraries. Across the board, majorities of category respondents indicate that a growth in fake news could be attributed to the emergence of computer/internet companies.

Figure 2 displays the role within libraries that respondents indicate they would most like to see AI introduced (example: "to develop resource recommendation systems for library patrons"). Support/improvement of the library discovery search is the overwhelmingly favorite selection, followed by reference services and cataloging assistance. Purchasing new acquisitions based on user resource selection behavior is an infrequent choice, as is using AI for organizational decision making. Among innovators, early adopters, and early majority, the frequencies follow the exact distribution frequency of the total survey population. For laggards and late majority, reference services and recommending materials are the second and third most common selections after library search.

Shown in table 3 is the Spearman correlation matrix for the variables included in this study. Strength of correlations may be interpreted based on the guidelines of Quinnipiac University: 


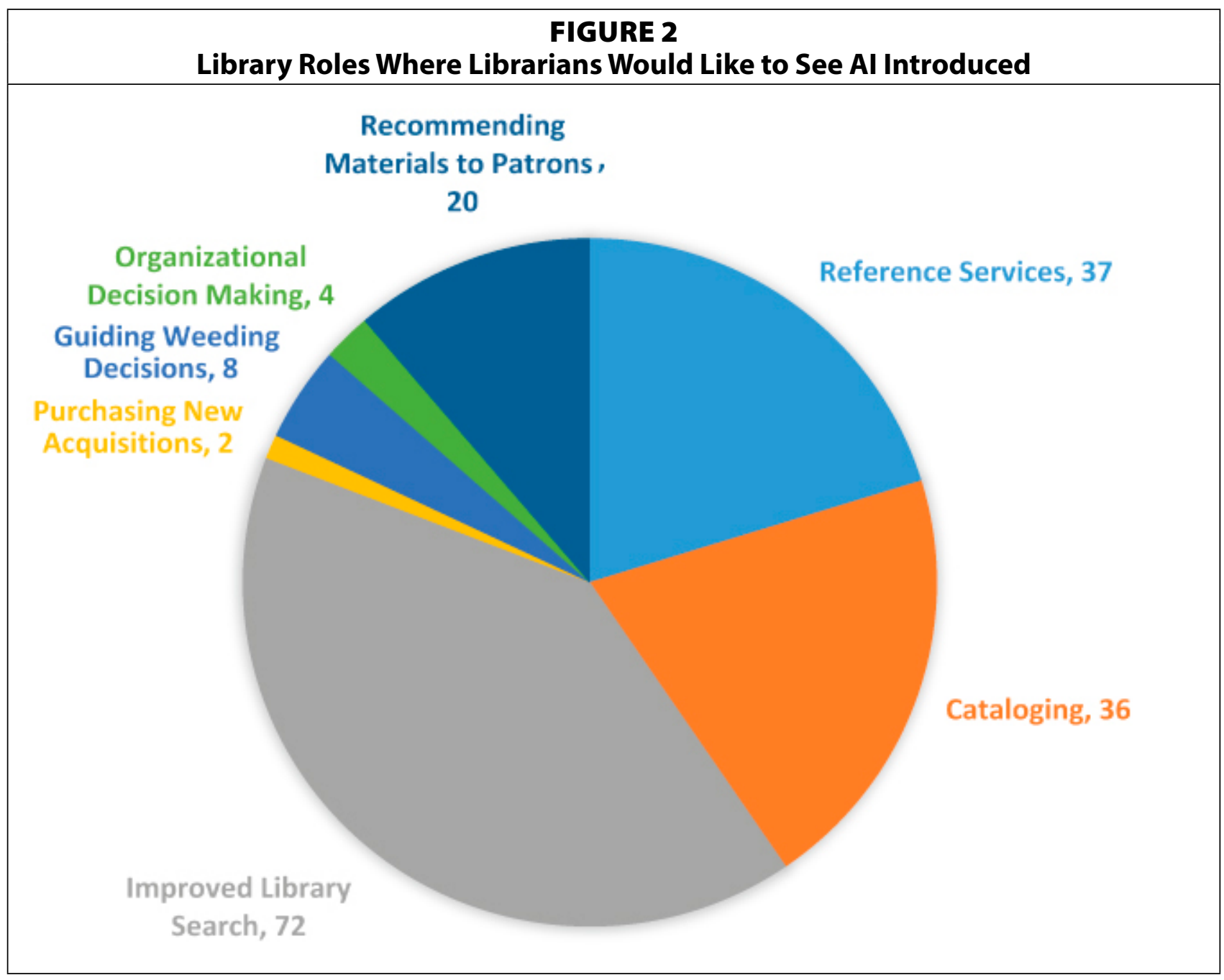

$0.1-0.2=$ weak correlation, $0.2-0.3=$ moderate correlation, $0.3-0.6=$ strong correlation, 0.6 and greater $=$ very strong correlation.${ }^{42}$ For most variables in the study, being ordinal type data, dummy variables were used (example: no $=0$, yes $=1$ ). For instance, for adopter category, the dummy variable is whether an individual is an "innovator/early adopter" (1) or "other" (0). Many of the variables have no statistically significant relationship with one another (statistical significance is indicated with an asterisk next to the value). Those variables that do have a statistically significant relationship include adopter category and how many hours per week scholarly literature is read (innovator/early adopter group reads more scholarly literature), optimism toward AI (innovator/early adopter group is more optimistic), knowledge of AI and fear of job loss from AI. A very strong relationship exists between the variables of optimism toward AI and knowledge of AI (those whose self-efficacy related to AI technology is high are also more optimistic regarding the potential uses for the technology). Strong relationships exist between the belief that AI will improve lives, the belief that AI presents privacy concerns, and the belief that growth in fake news is tied to the emergence of computer/internet companies and social media.

Displayed in table 4 is a linear regression model based on the dependent variable of adopter category ("innovator/early adopter" 1 , "other" 0 ) and the explanatory variables being those shown in the correlation matrix of table 5 . The resulting model has a R-squared value 


\begin{tabular}{|c|c|c|c|c|c|c|c|c|}
\hline \multicolumn{7}{|c|}{ SABLE 3 } \\
\hline Variable & $\begin{array}{c}\text { Adopter } \\
\text { Category }\end{array}$ & $\begin{array}{c}\text { Read } \\
\text { Literature }\end{array}$ & $\begin{array}{c}\text { Optimism } \\
\text { AI }\end{array}$ & $\begin{array}{c}\text { Knowledge } \\
\text { Al }\end{array}$ & $\begin{array}{c}\text { Fear Job } \\
\text { Loss AI }\end{array}$ & $\begin{array}{c}\text { Privacy } \\
\text { Concern }\end{array}$ & $\begin{array}{c}\text { Al } \\
\text { Improve } \\
\text { Life }\end{array}$ & $\begin{array}{c}\text { Fake } \\
\text { News } \\
\text { SM }\end{array}$ \\
\hline $\begin{array}{c}\text { Adopter } \\
\text { Category }\end{array}$ & 1 & $.371^{*}$ & $.333^{*}$ & $.333^{*}$ & $.353^{*}$ & .043 & $.240^{*}$ & -.034 \\
\hline $\begin{array}{c}\text { Read } \\
\text { Literature }\end{array}$ & $.371^{*}$ & 1 & -.024 & -.016 & $-.246^{*}$ & $-.246^{*}$ & -.191 & -.159 \\
\hline $\begin{array}{c}\text { Optimism } \\
\text { Al }\end{array}$ & $.333^{*}$ & -.024 & 1 & $.788^{*}$ & $-.072^{*}$ & $.422^{*}$ & .049 & .093 \\
\hline $\begin{array}{c}\text { Knowledge } \\
\text { Al }\end{array}$ & $.333^{*}$ & -.016 & $.78^{*}$ & 1 & $-.049^{*}$ & $.386^{*}$ & .013 & .099 \\
\hline $\begin{array}{c}\text { Fear Job } \\
\text { Loss Al }\end{array}$ & $.353^{*}$ & $-.246^{*}$ & -.072 & -.049 & 1 & -.145 & .006 & -.123 \\
\hline $\begin{array}{c}\text { Privacy } \\
\text { Concern }\end{array}$ & .043 & $-.246^{*}$ & $.422^{*}$ & $.386^{*}$ & -.145 & 1 & $.523^{*}$ & $.561^{*}$ \\
\hline $\begin{array}{c}\text { Al Improve } \\
\text { Life }\end{array}$ & $.240^{*}$ & -.191 & .049 & .013 & -.006 & $.523^{*}$ & 1 & $.653^{*}$ \\
\hline $\begin{array}{c}\text { Fake News } \\
\text { SM }\end{array}$ & -.034 & -.159 & .093 & .099 & -.123 & $.561^{*}$ & $.653^{*}$ & 1 \\
\hline$*$ Statistically Significant at p & & & & & & & & \\
\hline
\end{tabular}

of .720 ( $72 \%$ of variance in adopter category is addressed by the explanatory variables), a Fratio of 23 and $p<.001$.

Two of the explanatory variables were not significant factors in the model: privacy concern about AI and belief that the growth of fake news is tied to the emergence of computer/ internet companies and social media. In other words, privacy concern about AI and belief that the growth fake news is tied to the emergence of computer/internet companies and social media are not found to factors that help predict the adopter category of an individual. This finding is interesting in light of the correlation matrix, where these two variables were found to have a strong correlation with the belief that AI will improve lives. However, as indicated in figure 1, roughly 95 percent of respondents responded that they believe AI will improve lives, while 80 percent and 70 percent responded that they believed in the connection between internet companies and fake news and that they had privacy concerns, respectively. This suggests that these beliefs are shared among a majority of all respondents, independent of adopter category.

Two variables, in particular, have a very high level of predictive ability: optimism about $\mathrm{AI}$ and perceived knowledge of AI. Recall from the correlation matrix that these variables have a strong positive relationship. When used as explanatory variables, with the dependent variable of adopter category - as shown in table 5-the R-squared value is .604 with $p<.001$. Due to the close relationship between the two explanatory variables, a peculiar effect occurs 


\begin{tabular}{|l|c|c|c|c|c|}
\hline \multicolumn{7}{|c|}{ TABLE 4 } \\
Regression with All Variables (Dependent Variable of Adopter Category) \\
\hline Explanatory Variable & $\begin{array}{c}\text { Unstandardized } \\
\text { Beta }\end{array}$ & $\begin{array}{c}\text { Std. } \\
\text { Error }\end{array}$ & $\begin{array}{c}\text { Standardized } \\
\text { Beta }\end{array}$ & t-ratio & p-value \\
\hline How Often Scholarly Literature Read & .22 & .04 & .354 & 3.4 & $<.001$ \\
\hline Optimistic about Al & -1.9 & .52 & -9.86 & 3.4 & $<.001$ \\
\hline Knowledge of Al & 2.439 & .50 & 1.2 & 4.9 & $<.001$ \\
\hline Fear of Job Loss to Al & .482 & .152 & .33 & 3.18 & $<.01$ \\
\hline Privacy Concern about Al & .02 & .127 & .02 & .161 & .873 \\
\hline Al Improves Life & .494 & .180 & .357 & 2.746 & $<.05$ \\
\hline Fake News Tied to Social Media & -.257 & .161 & -.195 & -1.601 & .112 \\
\hline & & & & & \\
\hline Constant & -1.587 & & & & \\
\hline R2 & .720 & & & & \\
\hline F-ratio & 22.78 & $p<.001$ & & & \\
\hline SEE & .31 & & & & \\
\hline N & 236 & & & \\
\hline
\end{tabular}

among the betas, with optimism about AI taking a negative coefficient and knowledge about AI taking a positive coefficient. Since perceived knowledge of AI is generally slightly smaller than optimism toward AI- as shown in table 2-these betas nearly cancel out for the standard respondent; however, since the constant is .515, only a very small difference $(-.016)$ is needed to make the difference between the "innovator/early adopter" and "other" categories. This indicates that perceived knowledge and optimism about emerging technology is highly related to perceived adopter category among library employees.

\section{Discussion}

\section{Theoretical Implications}

The regression models indicate that a strong relationship exists between self-perception of knowledge of AI, optimism about AI, and adopter category. This result suggests that those who more readily adopt an emerging technology innovation like AI also tend to believe that

\begin{tabular}{|l|c|c|c|c|c|}
\hline \multicolumn{7}{|c|}{ Regression with Variables of Optimism and Knowledge of Al Only } \\
\hline Explanatory Variable & $\begin{array}{c}\text { Unstandardized } \\
\text { Beta }\end{array}$ & Std. Error & $\begin{array}{c}\text { Standardized } \\
\text { Beta }\end{array}$ & t-ratio & $p$-value \\
\hline Optimism about Al & -3.204 & .469 & -1.671 & -6.834 & $<.001$ \\
\hline Knowledge of Al & 3.565 & .498 & 1.752 & 7.164 & $<.001$ \\
\hline & & & & & \\
\hline Constant & .515 & & & & \\
\hline $\mathrm{R}^{2}$ & .604 & & & & \\
\hline F-ratio & 25.903 & $p<.001$ & & & \\
\hline SEE & .36 & & & & \\
\hline $\mathrm{N}$ & 236 & & & & \\
\hline
\end{tabular}


they have a higher knowledge of emerging technologies and a more optimistic outlook for these technologies. This finding may be a bit obvious (that early adopters would also perceive themselves as more knowledgeable and optimistic about what they adopt), but it does provide some empirical support that adopter category affiliation is connected to perception of self. This aligns with the findings of researchers like Ellen, Bearden, and Sharma, who connected Diffusion of Innovations research to the self-efficacy concepts of Bandura. ${ }^{43}$

Additionally, those who are innovators, early adopters, and early majority (top half of adopters) read scholarly literature much more on average than the late majority and laggards (bottom half of adopters). This suggests psychological and behavioral (including information behavior) differences exist among earlier adopters and later adopters, which is not altogether surprising given prior research by Chatman and others, ${ }^{44}$ but nonetheless is further evidence of the phenomenon.

In general, respondents to this study held an optimistic outlook toward AI and its potential use within libraries. While there was a concern by some respondents about AI replacing their job roles, this was a minority perception. This result would support a hypothesis that academic librarians in general have a favorable opinion of emerging technologies and their integration into library services, and it also aligns well with the findings of the adopter categories, where the majority fell within the categories of either early adopter or early majority.

The Diffusion of Innovations framework, in general, is one that could be applied more frequently in LIS research, as it has great relevance to many studies published in the literature of the discipline today. This study demonstrates one way in which the framework may be successfully employed in a study of library employee perspectives/attitudes. The framework is particularly useful for policy and prediction studies, as might be conducted using a Delphi approach, as well as the identification of social and technological barriers for certain populations.

\section{Practical Implications}

As mentioned in the theoretical implications section above, the Diffusion of Innovations framework can be a beneficial framework for the development of institutional policy. This use for policy development is common because the framework leads the researcher to identify differences that exist among the adoption of different groups of people and explore why the differences occur (barriers, beliefs, stubbornness?). In line with this perspective, some policy implications may be gleaned from this study. For instance, the interest and optimism toward artificial intelligence among the sample of librarians in this study, and the alignment of librarians as early adopters, indicates that AI may be an area that academic libraries are ready to explore on a deeper level and that appropriate funding from agencies such as the Institute of Museum and Library Services (IMLS) could be well-warranted. Perhaps, given their positive inclination, librarians could even take the lead in designing and integrating practical uses of AI technology into library systems and services and educating patrons, much as they may have done in the early days of the internet ${ }^{45}$ or similarly to how San Jose State University has done with its blockchain project. ${ }^{46}$

Participants in this study made it very clear in which aspects they would like to see AI technologies integrated and which aspects they would not. Improving library search, expediting cataloging, and assisting with reference services were all areas that rated highly, while purchasing and organizational decision making were areas that participants did not have interest in AI being integrated. The former roles (library search, cataloging, and reference 
service) would include automation in the form of library search that is more predictive of user behavior (like a more search engine-type feel), automated entry of metadata for materials, and use of automated programs to respond to basic library reference questions (like a "Siri"-type service). The latter roles would consist of such tasks as determining what materials should be purchased by the library using an algorithm that identifies patterns in the use of library materials (essentially, automated collection development) and identifying areas where departments or physical spaces in the library may reorganize based on patron use patterns (automated planning and management). These findings about library preferences toward AI use may be important takeaways for library professionals and administrators that indicates in which aspects participants were responsive to the idea of partial or full automation. There are many research advances published every year in the use of AI for improving information retrieval. ${ }^{47}$ If this is an area of interest to the library community, it may be possible to begin developing systems based on these principles and best practices and investigating the feasibility of implementing them.

Artificial intelligence technologies are already being implemented in libraries to varying degrees, as noted by Thomas Finley; ${ }^{48}$ it is merely the extent that varies. Virtually any product a library uses, from a search engine to a wayfinding (Google Maps) site, uses AI to find solutions to complex problems that previously only the human mind would be able to solve ("which routes are fastest?"). Some libraries have taken the implementation of AI beyond this boundary. Finley's library capitalized on the growing interest in AI by distributing AI kits to patrons for the purpose of exploring the technology and developing their own basic program idea (similar to STEM kits). Stanford University Libraries' artificial intelligence project has developed a lecture series and research agenda aimed at exploring the uses of AI within libraries and information organizations. ${ }^{49}$ With the high level of interest in AI demonstrated in this study, more libraries may soon become interested in projects of this type.

\section{Limitations and Future Research}

There are some limitations to the data and the statistical tests chosen for analysis. The distribution of the adopter categories follows an abnormal distribution. Though the population size is significantly large to indicate that this skew may be representative of the whole of librarianship (central limit), and distribution of standard error (normal) is more important than distribution of data, there is still a limitation to using linear regression for skewed data. Several researchers have suggested that it is acceptable to use standard multiple linear regression for abnormal data, assuming the abnormality is made explicit to the reader. ${ }^{50}$ Given the high statistical power of linear regression, this method was chosen for analysis while acknowledging this limitation.

Further research may examine whether findings pertaining to the distribution of adopters of innovations is consistent across librarianship and investigate further the relationships between the self-identified variables of perceived knowledge of innovations, optimism toward innovations, and adoption of innovations. These three variables appear to have a powerful relationship, suggesting that barriers to diffusion may be not only lack of knowledge of innovations (is traditional in the diffusion model), but also level of optimism toward the future of these innovations (that is to say, librarians do not want to waste time with a library technology that might just be a fad). An investigation of library users' perspectives on these questions may also prove valuable. Further exploration of the practical implications from this 
study may also be warranted (How can optimism toward innovations in library technology be increased? This study indicates that information/knowledge plays a major role).

\section{Conclusion}

In the present study, academic librarians responding to the survey were highly receptive toward the potential of integrating artificial intelligence into the operations of the library and demonstrated that they are generally early adopters of new information and communications technologies. While Cox et al. suggest that "IT services might be in a stronger natural position to take on some of these (AI management) roles," 51 the present study indicates that, at least in some instances, academic librarians are eager and prepared to take the lead in these roles.

The impetus for adoption of an innovation like AI falls largely upon early adopters, as it is often these individuals on whom the other categories rely to determine whether an innovation has value. ${ }^{52}$ Given that many of the early adopters in this study expressed positive views toward artificial intelligence being used in a number of ways within the library environment, there is a good indication that this technology will play a major role in library service in years to come. Advocates' best tool, as suggested by Rogers himself when describing diffusion as a process of information exchange, is information about the innovation (what it is, how it works, what benefits it could provide, cost/benefit analysis, project management needs) and ensuring that it is disseminated to the major decision makers within the library. 


\section{APPENDIX. Survey of Library Employee Perspectives toward Artificial Intelligence}

Q1. Please indicate your gender

$\square \quad$ Male

$\square$ Female

$\square \quad$ Prefer not to say

Q2. Please indicate your age

29 and under

30-39

$40-49$

50-59

$\square \quad 60$ or over

Q3. Please indicate your highest level of educational achievement

$\square \quad$ No degree

$\square$ High school degree

$\square$ Some college

$\square \quad$ Two-year college degree

$\square \quad$ Four-year undergraduate degree

$\square$ Graduate degree

$\square \quad \mathrm{PhD}$

Q4. Please indicate your current working status

$\square$ Currently working

$\square \quad$ Not currently working

Q5. Please indicate the continent on which you work

$\square$ North America

$\square$ South America

$\square$ Europe

$\square$ Africa

$\square$ Asia

- Australia

Q6. In general, I am...

The very first person to adopt a new idea or way of thinking

$\square \quad$ One of the first to adopt...

$\square$ Not one of the first, but ahead of the majority

$\square$ About middle of the pack

$\square$ Very late

$\square \quad$ I almost never adopt a new idea or way of thinking

Q7. In general, I am

$\square \quad$ The very first person to use a new technology

口 One of the first to use...

$\square$ Not one of the first, but ahead of the majority

$\square$ About middle of the pack

$\square$ Very late

$\square \quad$ I almost never use a new technology 
Q8. How often do you read professional literature/research?

$\square$ Almost never

$\square \quad$ Less than 1 hour a month

$\square$ Less than 1 hour a week

1-3 hours a week

$\square$ 3-6 hours a week

$\square$ 6-15 hours a week

More than 15 hours a week

Q9. Please indicate your response for the following items (Seven-point Likert scale)

Rate your knowledge of artificial intelligence as a concept

Rate your knowledge of trends in artificial intelligence

Rate your level of optimism about the future of artificial intelligence for improving library service Q10. Regarding the future of artificial intelligence and robotics...

$\square \quad$ I am afraid I might lose my job as AI becomes more advanced

I don't think my job will be at risk

I don't know

Q11. In what aspects of the library environment would you like to see AI introduced?

Reference services

$\square$ Cataloging

$\square \quad$ Improved library search

口 Purchasing new acquisitions

․ Guiding weeding decisions

Organizational decision making

$\square$ Recommending materials to patrons

$\square \quad$ Other (please specify)

Q12. Do you have privacy concerns about AI in the library environment?

Yes

$\square$ No

口 I don't know

Q13. Do you believe advanced AI will improve the lives of people?

口 Yes

$\square$ No

I don't know

Q14. In general, I believe that the major computer/internet-based companies and conglomerates (like Google, Facebook, Microsoft, Apple, IBM) contribute to the good of society

口 Yes

$\square$ No

I don't know

Q15. In general, I believe that the major computer/internet-based companies and conglomerates (like Google, Facebook, Microsoft, Apple, IBM) contribute to the good of libraries

口 Yes

口 No

I don't know 


\title{
Q16. Do you believe the rise of "fake news" is related to the emergence of major computer/ internet-based companies and conglomerates (like Google, Facebook, Microsoft, Apple, IBM)?
}

\author{
$\square$ Yes \\ $\square$ No \\ I don't know
}

\section{Notes}

1. Waqar Ahmed, "Third Generation of the Web: Libraries, Librarians and Web 3.0," Library Hi Tech News 32, no. 4 (2015): 6-8; Nancy B. Talley, "Imagining the Use of Intelligent Agents and Artificial Intelligence in Academic Law Libraries," Law Library Journal 108, no. 3 (2016): 384-402; Andrew M. Cox et al., "Maturing Research Data Services and the Transformation of Academic Libraries," Journal of Documentation 75, no. 6 (2019): 1432-62.

2. Bernard Marr, "The Key Definitions of Artificial Intelligence That Explain Its Importance," Forbes, available at https://www.forbes.com/sites/bernardmarr/2018/02/14/the-key-definitions-of-artificial-intelligence-ai-thatexplain-its-importance/\#3e94804d4f5d [accessed September 20, 2019]. $1-3$.

3. Stuart J. Russell and Peter Norvig, Artificial Intelligence: A Modern Approach (London, UK: Pearson, 2016),

4. Andrew M. Cox, Stephen Pinfield, and Sophie Rutter, “The Intelligent Library: Thought Leaders' View on the Likely Impact of Artificial Intelligence on Academic Libraries," Library Hi Tech 37, no. 3 (2019): 418-35.

5. Luke Tredinnick, "Artificial Intelligence and Professional Roles," Business Information Review 34, no. 1 (2017): 37-41.

6. Keith Frankish and William M. Ramsey, The Cambridge Handbook of Artificial Intelligence (Cambridge, UK: Cambridge University Press, 2014), 1.

7. Isaiah M. Omame and Juliet Alex-Nmeche, "Artificial Intelligence in Libraries," manuscript in preparation.

8. Russell and Norvig, Artificial Intelligence: A Modern Approach.

9. Ajay Agrawal, "The Economics of Artificial Intelligence," The National Bureau of Economic Research, available at https://conference.nber.org/conferences/2017/AIf17/summary.html [accessed May 20, 2019].

10. F. Wilfrid Lancaster, Uses of Computers in Literature Searching and Related Activities in Libraries (Champaign, IL: University of Illinois, 1975); F. Wilfrid Lancaster, Libraries and the Future: Essays on the Library in the TwentyFirst Century (Abingdon, UK: Routledge, 1993).

11. Tom Surprenant, "Future Libraries," Wilson Library Bulletin 58 (1983): 207.

12. Linda C. Smith, "Artificial Intelligence and Information Retrieval," Annual Review of Information Science and Technology 22 (1987): 41-77.

13. John A. Mess, "Artificial Intelligence in Information Services: Revolution or Survival?" Proceedings of the 1991 IATUL Conference (1991): Paper 8, https://docs.lib.purdue.edu/cgi/viewcontent.cgi?article=1143\&context=iatul.

14. Asefeh Asemi and Adeleh Asemi, "Artificial Intelligence Application in Library Systems in Iran: A Taxonomy Study," Library Philosophy and Practice (December 2018): 1840, https://digitalcommons.unl.edu/libphilprac/1840.

15. Nancy B. Talley, "Imagining the Use of Intelligent Agents and Artificial Intelligence in Academic Law Libraries," Law Library Journal 108, no. 3 (2016): 383-402, https://doi.org/https://doi.org/10.7282/T3Z03C65.

16. Thomas Finley, "The Democratization of Artificial Intelligence: One Library's Approach," Information Technology and Libraries 38, no. 1 (March 2019): 8-13, https://doi.org/10.6017/ital.v38i1.10974.

17. Barbara A. Wood and David Evans, "Librarians' Perceptions of Artificial Intelligence and Its Potential Impact on the Profession," Computers in Libraries 38, no. 1 (2018), http://www.infotoday.com/cilmag/jan18/WoodEvans--Librarians-Perceptions-of-Artificial-Intelligence.shtml.

18. Wood and Evans, "Librarians' Perceptions of Artificial Intelligence and Its Potential Impact on the Profession."

19. Cox, Pinfield, and Rutter, "The Intelligent Library."

20. Cox, Pinfield, and Rutter, "The Intelligent Library," 418.

21. Loida Garcia-Febo, "Exploring AI: How Libraries Are Starting to Apply Artificial Intelligence in Their Work," American Libraries (March 2019), https://americanlibrariesmagazine.org/2019/03/01/exploring-ai/.

22. Geoff Mulgan, "The Theoretical Foundations of Social Innovation," in Social Innovation (London, UK: Palgrave MacMillan, 2012), 33-65. 
23. Everett M. Rogers, Diffusion of Innovations (New York, NY: Free Press, 2003$), 172$.

24. Marilyn D. White, "Diffusion of an Innovation: Digital Reference Service in Carnegie Foundation Master's Academic Institution Libraries," Journal of Academic Librarianship 27, no. 3 (May 2001): 173-87, https://doi. org/10.1016/S0099-1333(01)00179-3.

25. Mabel K. Minishi-Majanja and Joseph Kiplang'at, "The Diffusion of Innovations Theory as a Theoretical Framework in Library and Information Science Research," South African Journal of Libraries and Information Science 71, no. 3 (January 2005): 211-24.

26. Yujia Zhai, Ying Ding, and Fang Wang, "Measuring the Diffusion of an Innovation: A Citation Analysis," Journal of the Association for Information Science and Technology 69, no. 3 (2018): 368-79.

27. Rogers, Diffusion of Innovations, 262-66.

28. Shampa Iftakhar, "Google Classroom: What Works and How?" Journal of Education and Social Sciences 3, no. 1 (February 2016): 12-18.

29. James C. Brancheau, “The Diffusion of Information Technology: Testing and Extending Innovation Diffusion Theory in the Context of End-User Computing" (PhD diss., University of Minnesota, 1987), Proquest Dissertation and Theses (8805697); Paul A. Geroski, "Models of Technology Diffusion," Research Policy 29, no. 4/5 (April 2000): 603-25, https://doi.org/10.1016/S0048-7333(99)00092-X.

30. Everett M. Rogers, Communications Technology (New York, NY: Simon \& Schuster, 1986).

31. Nagy Hanna, Ken Guy, and Erin Arnold, The Diffusion of Information Technology: Experience of Industrial Countries and Lessons for Developing Countries (The World Bank, 1995).

32. Sandra Valenti, "Understanding Factors for Innovation Adoption in Higher Education Courses: A Case Study Approach" (PhD diss., Emporia State University, 2015).

33. Emily Neo and Phillip J. Calvert, "Facebook and the Diffusion of Innovation in New Zealand Public Libraries," Journal of Librarianship and Information Science 44, no. 4 (2012): 227-37.

34. Ding-Yu Liu and Kuei-Shu Hsu, "A Study on User Behavior Analysis of Integrate Beacon Technology into Library Information Services," Eurasian Journal of Mathematics, Science and Technology Education 14, no. 5 (2018): 1987-97.

35. Wasim Qazi, Syed A. Raza, and Nida Shah, "Acceptance of E-book Reading among Higher Education Students in a Developing Country: The Modified Diffusion Innovation Theory," International Journal of Business Information Systems 27, no. 2 (2018): 222-45.

36. Ritu Agarwal et al., "Early and Late Adopters of IT Innovations: Extensions to Innovation Diffusion Theory," Proceedings of the DIGIT Conference, 1998 (September 1998): 1-18.

37. Nese Zayim, Soner Yildirim, and Osman Saka, "Technology Adoption of Medical Faculty in Teaching: Differentiating Factors in Adopter Categories," Educational Technology and Society 9, no. 2 (2006): 213-22.

38. Melissa Raynard, "Understanding Academic E-books through the Diffusion of Innovations Theory as a Basis for Developing Effective Marketing and Educational Strategies," Journal of Academic Librarianship 43, no. 1 (January 2017): 82-86, https://doi.org/10.1016/j.acalib.2016.08.011.

39. Matt Holland, "Diffusion of Innovation Theories and Their Relevance to Understanding the Role of Librarians When Introducing Users to Networked Information," Electronic Library 15, no. 5 (1997): 389-94.

40. Jagdish N. Sheth and Walter H. Stellner, Psychology of Innovation Resistance: The Less Developed Concept (LDC) in Diffusion Research (Champaign, IL: University of Illinois, 1979); Sara F. Fine, "Technological Innovation, Diffusion and Resistance," Journal of Library Administration 7, no. 1 (1986): 83-108.

41. James E. Bartlett, Joe W. Kotrlik, and Chadwick C. Higgins, "Organization Research: Determining Appropriate Sample Size in Survey Research," Information Technology, Learning, and Performance Journal 19, no. 1 (2001): 43-50.

42. Haldun Akoglu, “User's Guide to Correlation Coefficients," Turkish Journal of Emergency Medicine 18, no. 3 (2018): 91-93.

43. Pam S. Ellen, William O. Bearden, and Subhash Sharma, "Resistance to Technological Innovations: An Examination of the Role of Self-efficacy and Performance Satisfaction," Journal of the Academy of Marketing Science 19, no. 4 (1991): 297-307; Albert Bandura, "Self-efficacy: Toward a Unifying Theory of Behavioral Change," Psychological Review 84 (1977): 191-215.

44. Elfreda Chatman, "Diffusion Theory: A Review and Test of a Conceptual Model in Information Diffusion," Journal of the Association for Information Science and Technology 37, no. 6 (1986): 377-86.

45. Roy Tennant, "Internet Basic Training: Teaching Networking Skills in Higher Education," Internet Research 1, no. 2 (1991): 37-46; Ilene F. Rockman, "Teaching about the Internet: The Formal Course Option," Reference Librarian 18, no. 39 (1993): 65-75.

46. San Jose State University, Blockchains for the Information Profession, https://ischoolblogs.sjsu.edu/blockchains/ [accessed September 11, 2019)] 
47. Avneet Pannu, "Artificial Intelligence and Its Application in different areas," International Journal of Engineering and Innovative Technology 4, no. 10 (2015): 79-84; Spyros Makridakis, "The Forthcoming Artificial Intelligence Revolution: Its Impact on Society and Firms," Futures 90 (March 2017): 46-60.

48. Thomas Finley, "The Democratization of Artificial Intelligence: One Library's Approach," Information Technology and Libraries 38, no. 1 (2019): 8-13.

49. Stanford University Libraries, Artificial Intelligence, https://library.stanford.edu/projects/artificial-intelligence [accessed December 4, 2019].

50. Douglas C. Montgomery, Elizabeth A. Peck, and G. Geoffrey Vining, Introduction to Linear Regression Analysis (New York, NY: John Wiley and Sons, 2012); Matt N. Williams, Carlos A.G. Grajales, and Dason Kurkiewicz, "Assumptions of Multiple Regression: Correcting Two Misconceptions," Practical Assessment, Research and Evaluation 18, no. 11 (September 2013): 1-14, https://pareonline.net/getvn.asp?v=18\&n=11.

51. Cox, Pinfield, and Rutter, "The Intelligent Library," 430.

52. Theo Lynn et al., "Social Network Sites: Early Adopters' Personality and Influence," Journal of Product and Brand Management 26, no. 1 (2017): 42-51; Rogers, Diffusion of Innovations. 